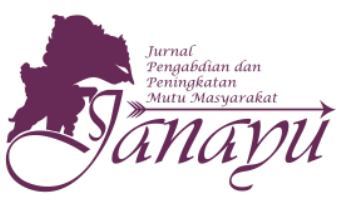

Website:

ejournal.umm.ac.id/index.php/janayu

Afiliasi:

${ }^{1}$ Fakultas Ekonomi dan Bisnis, Universitas Muhammadiyah Malang, Malang, Jawa Timur, Indonesia

*Correspondence:

ikearisanti@umm.ac.id

DOI: $\underline{10.22219 / \text { janayu.v1i2.12471 }}$

Sitasi:

Widyastuti, A, Jati, A.W. \& Arisanti,

I. (2020). Pendampingan Administrasi Pengajuan Legalitas SD

Muhammadiyah 4 Kota Batu. Jurnal

Pengabdian dan Peningkatan Mutu

Masyarakat, 1(2), 117-125.

Proses Artikel

Diajukan:

11 Juni 2020

Direviu:

24 Juni 2020

Direvisi:

7 Juli 2020

Diterima:

23 Juli 2020

Diterbitkan:

29 Juli 2020

Alamat Kantor:

Jurusan Akuntansi Universitas

Muhammadiyah Malang

Gedung Kuliah Bersama 2

Lantai 3.

Jalan Raya Tlogomas 246,

Malang, Jawa Timur,

Indonesia

P-ISSN: 2721-0421

E-ISSN: 2721-0340
Tipe Artikel: Paper Pengabdian

\section{Pendampingan Administrasi Pengajuan Legalitas SD Muhammadiyah 4 Kota Batu Aviani Widyastuti ${ }^{1}$, Ahmad Waluya Jati ${ }^{1}$, Ike Arisanti ${ }^{*}$}

\section{ABSTRACT}

This community service activity aims to assist in the improvement and control of legality administration in one of the Muhammadiyah Business Charities (AUM) in Batu City, namely $S D$ Muhammadiyah 4. The administration improvement and control referred to in this case is related to the maintenance of AUM establishment permits that are aligned with the status of AUM legal entity namely Business Identification Number (NIB) and uniformity of Taxpayer Identification Number (NPWP). This activity will be carried out in three stages, namely the NIB management stage, the financial reporting and taxation stage and the AUM governance stage. However, in this service activity it was proposed as a form of solving the problems of SD Muhammadiyah 4 Kota Batu for the first stage, namely the management of NIB. Problem solving in the first phase of this activity is to use the methods of presentation, training and assistance as well as dialogue. The outputs of the devotion activities in this first stage are SD Muhammadiyah Kota Batu can arrange and complete licensing administration procedures related to NIB and uniformity of NPWP.

KEYWORDS: Muhammadiyah Charitable Enterprises; Main Business Number;NPWP

\section{ABSTRAK}

Kegiatan pengabdian kepada masyarakat ini bertujuan untuk memberikan pendampingan dalam perbaikan dan penertiban administrasi legalitas pada salah satu Amal Usaha Muhammadiyah (AUM) di Kota Batu yaitu SD Muhammadiyah 4. Perbaikan dan penertiban administrasi yang dimaksud dalam hal ini adalah terkait dengan pengurusan ijin pendirian AUM yang selaras dengan status badan hukum AUM yaitu Nomor Induk Berusaha (NIB) dan penyeragaman Nomor Induk Wajib Pajak (NPWP). Kegiatan ini pada dasarnya akan dilakukan dalam tiga tahapan yaitu tahap pengurusan NIB, tahap Pelaporan keuangan dan perpajakan dan tahap tata kelola AUM. Akan tetapi pada kegiatan pengabdian ini diajukan sebagai bentuk penyelesaian permasalahan SD Muhammadiyah 4 Kota Batu untuk tahap pertama yaitu pengurusan NIB. Penyelesaian permasalahan pada tahap pertama kegiatan ini adalah dengan menggunakan metode presentasi, pelatihan dan pendampingan serta dialog. Adapun luaran dari kegiatan pengabdian pada tahap pertama ini adalah SD Muhammadiyah Kota Batu dapat mengurus dan menyelesaikan prosedur administrasi perijinan terkait NIB serta penyeragaman NPWP.

KATA KUNCI: Amal Usaha Muhammadiyah; Nomor Induk Berusaha; NPWP 
Widyastuti, Jati \& Arisanti, Pendampingan Administrasi Pengajuan ...

\section{PENDAHULUAN}

Muhammadiyah dikenal sebagai gerakan terbesar di dunia yang membawa pengaruh yang sangat pesat dalam kehidupan bangsa terutama dalam kehidupan ummat Islam. Dengan tujuan untuk membasmi TBC (Tahayyul, Bid'ah dan Khurafat) membawa Muhammadiyah sangat diingini keberaidaanya di tengah-tengah masyarakat. Hal ini terbukti dengan mudahnya Muhammadiyah menyebar di tengah-tengah masyarakat Indonesia (Gusfira, 2017).

Maksud dan tujuan Muhammadiyah menurut Anggaran Dasar Muhammadiyah Pasal 6 ialah menegakkan dan menjunjung tinggi Agama Islam sehingga terwujud masyarakat Islam yang sesuai dengan Al- Quran dan Sunnah Rasul. Dari maksud dan tujuan tersebut Muhammadiyah selalu berjuang untuk: Mengamalkan agama Islam di tengah- tengah masyarakat, terlebih-lebih di kalangan anggotanya; Membentuk masyarakat utama, adil, dan makmur yang baik agamanya, baik persaudaraannya dan baik pula ekonominya yaitu dengan mengadakan pengajian, tolong-menolong dan membentuk koperasi simpan pinjam; Selalu berjuang untuk mendapatkan keridhaan Allah dan dalam berbuat di Muhammadiyah selalu mempertimbangkan apakah perbuatannya diridhai Allah atau mungkin dimurkai Allah (Purba \& Ponirin, 2017).

Untuk mencapai maksud dan tujuan Muhammadiyah yaitu dengan melaksanakan Da'wah Amar Ma'ruf Nahi Munkar yang diwujudkan dalam usaha dibidang Agama, Pendidikan, Sosial dan Ekonomi. Usaha Muhammadiyah diwujudkan dalam bentuk amal usaha, program dan kegiatan yang penyelenggarannya diatur dalam Anggaran Rumah Tangga (ART) dan Anggaran Dasar (AD) Muhammadiyah (Akbar dkk., 2018).

Amal usaha Muhammadiyah secara garis dapat dikelompokkan dalam dua bidang yaitu: Pendidikan dan Kesehatan. Pendidikan adalah gerakan gerakan Muhammadiyah harus diakui bahwa gerakan dibidang pendidikanlah yang menempati urutan teratas. Jangkuan kegiatannya dimulai dari Taman Kanak- Kanak "Bustanul Athfal", Pondok Pesantren, Sekolah Umum, Kejuruan, Madrasah hingga Perguruan Tinggi (Susilo, 2016). Menurut Subarkah (2017) Salah satu sebab didirikannya Muhammadiyah ialah karena lembagalembaga pendidikan di Indonesia sudah tidak memenuhi lagi kebutuhan dan tuntutan zaman. Tujuan pendidikan yang sampai saat ini menjadi rujukan bagi perguruan Muhammadiyah adalah sebagaimana tentang Qoidah Pendidikan Dasar dan Menengah Bab I Pasal 3, sebagai berikut: Pendidikan Dasar dan Menengah Muhammadiyah bertujuan: Membentuk manusia muslim yang beriman, bertaqwa, berakhlak mulia, cakap, percaya pada diri sendiri, berdisplin, bertanggung jawab, cinta tanah air, memajukan dan memperkembangkan ilmu pengetahuan dan keterampilan dan beramal menuju terwujudnya masyarakat utama, adil dan makmur yang dridhai Allah SWT. (Khozin, 2005: 43).

Menurut Susilo (2016) muhammadiyah dalam kebijakan yang dirumuskan dalam Muktamar di Malang tahun 2005 tentang mutu pendidikan, menjadi menjadi hal mendasar yang harus disegerakan oleh sekolah muhammadiyah. Salah satu terobosan program yang digulirkan adalah pengembangan sekolah mandiri. Pengembangan kemandirian sekolah atau sekolahmandiri muhammadiyah tidak akan bisa terimplimentasi jika tidak ada kebijakan sekolah tentang hal tersebut. Kebijakan merupakan langkah awal yang merupakan strategi pembuka untuk mewujudkan sekolah yang bermutu. Zamroni (2005:2-4) menyebutkan bahwa strategi kebijakan dalam rangka peningkatan mutu pendidikan dapat dipilih strategi yang menekankan hasil/kualitas lulusan (the output oriented strategy), strategi yang menekankan proses (the process oriented strategy), dan strategi komprehensif (the comprehensive strategy). Atas dasar pendekatan dan

\section{Janayu} 1.2 
strategi kebijakan di atas, maka aneka kebijakan nyata secara strategis banyak dilakukan oleh pemerintah Indonesia dengan berujung peningkatan mutu pendidikan, seperti: kebijakan yang menyangkut KTSP, akreditasi sekolah, BOS, akses buku melalui ebooks, pengembangan kultur sekolah, perbaikan manajemen sekolah, UAN, sekolah berstandar internasional, peningkatan mutu guru, dan lain sebagainya (Arief Rohman \& Teguh Wiyono, 2010:14).

Diterbitkannya Peraturan Pemerintah (PP) nomor 24 tahun 2018 tentang Pelayanan Perizinan Berusaha Terintegrasi secara elektronik mengharuskan seluruh lembaga usaha memiliki Nomor Induk Berusaha (NIB) dan NPWP. NIB sendiri merupakan nomor induk yang wajib dimiliki semua komponan lembaga usaha baik yang profit atau non profit. NIB dapat digunakan untuk pendirian dan perpanjangan AUM, Ijin Prodi Baru, Ijin IMB, Ijin Operasi, dll. Terdapat 20 sektor usaha yang terdampak regulasi NIB (gambar 1). Selain itu berdasarkan data tim pajak dan nib PP Muhammadiyah ada beberapa risiko yang telah terjadi di AUM karena tidak memiliki Nib diantaranya SMK Muhammadiyah Panji guru tidak bisa mencairkan tunjangan guru, SMK Muhammadiyah 5 Kepanjen jurusan baru perfilman tidak dapat melakukan akreditasi karena terkendala ijin, dll

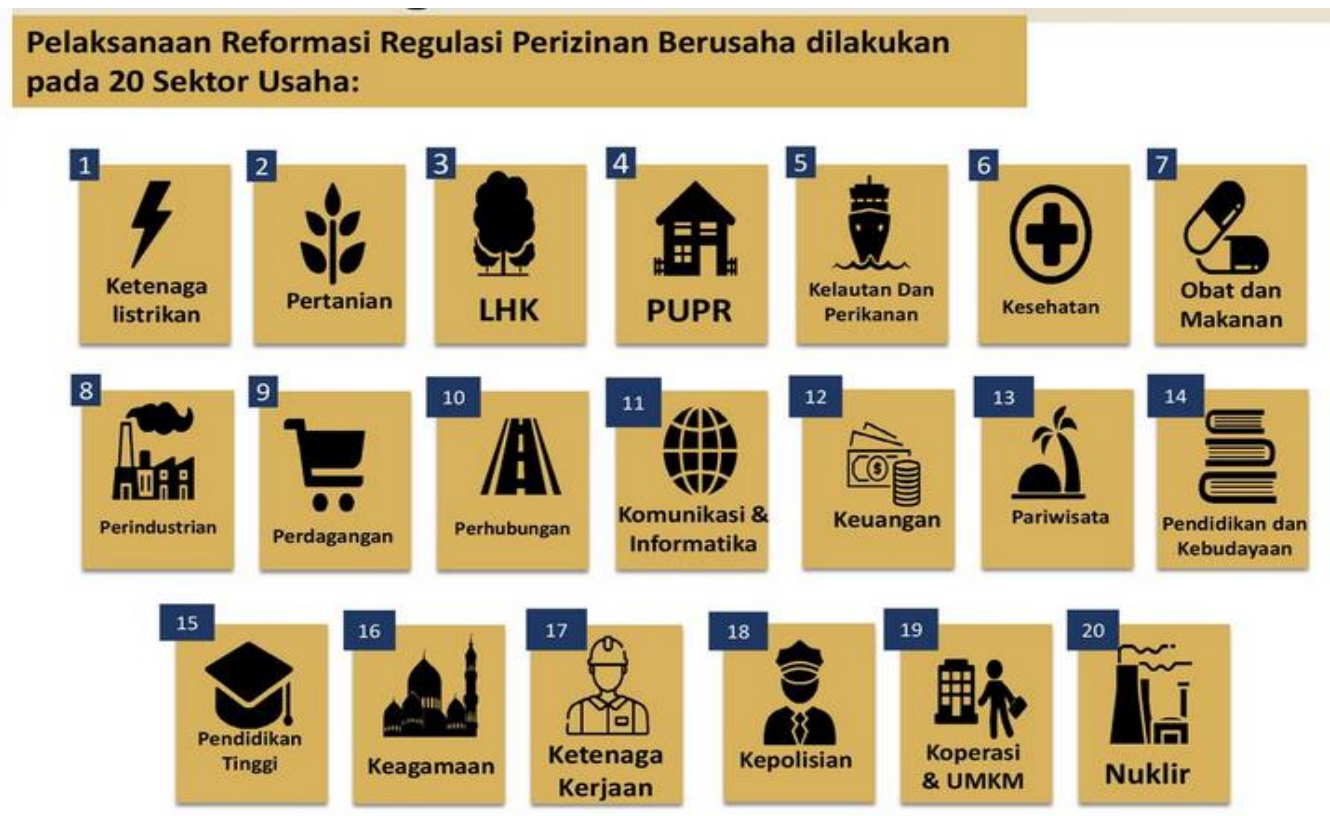

Gambar 1.

20 sektor usaha yang terdampak regulasi NIB

\section{Janayu}

1.2

Amal Usaha Muhammadiyah di Kota Batu sudah ada beberapa yang memilki NPWP tetapi atas nama PP Muhammadiyah. Selain itu kurang dari 50\% AUM di Kota Batu yang memiliki NIB hal ini terjadi karena kurangnya pengetahuan terkait perundang undangan tentang wajib NIB sebagian besar AUM di Kota Batu. Kendala lainnya yaitu pada akte pendirian AUM, nama AUM terdaftar atas nama yayasan BUKAN persyarikatan. Hal tersebut tentunya tidak sesuai dengan bentuk organisasi Muhammadiyah yang berbentuk persyarikatan dan dapat memengaruhi operasional AUM. Kepemilikan NIB dapat menunjang kelancaran operasional dan keberlanjutan AUM. Jika tidak, maka hal tersebut dapat memengaruhi aktivitas AUM. Misalnya pada AUM di bidang pendidikan yang tidak memiliki NIB. Jika hal tersebut terjadi, maka AUM tersebut tidak dapat menerima siswa baru, tidak mendapatkan BOP (Bantuan Operasional Pendidikan), sekolah dibekukan atau digabungkan dengan sekolah lain, tidak dapat membuka jurusan baru (SMK), hingga pihak 
sekolah tidak diizinkan menandatangani ijazah. Demikian halnya dengan AUM di bidang kesehatan. Jika AUM tersebut belum memiliki NIB, maka izin operasional klinik tidak diberikan, tidak bisa diperpanjang, dan BPJS akan diputus.

Salah satu Amal usaha yang belum memiliki NIB adalah SD Muhammadiyah 4 Batu. SD Muhammadiyah 4 Kota Batu terletak di Jalan Welirang 17, Sisir Kota Batu Muhammadiyah 4 Kota Batu memiliki jumlah siswa sebanyak 728 siswa dan 46 Guru (dapo.dikdasmen.kemdikbud.go.id). Menurut kepala sekolah SD Muhammadiyah 4 Kota Batu salah satu permasalahan adalah tidak memiliki NIB sehingga dampaknya kedepannya adalah tidak dapat mencairkan dana BOS ataupun pendanaan yang lainnya. Selain itu kepemilikan NIB merupakan salah satu wujud kemandirian sekolah. Menurut Wahab dalam Susilo (2016) mengatakan bahwa Sekolah Kategori Mandiri (SKM): sekolah yang mampu mengoptimasikan pencapaian tujuan pendidikan, potensi dan sumberdaya yang dimiliki untuk melaksanakan proses pembelajaran yang dapat mengembang kan potensi peserta didik sehingga menghasilkan lulusan yang berkualitas. Berdasarkan analisis situasi di SD Muhammadiyah 4 Kota Batu tersebut mendasari pentingnya kegiatan pengabdian ini dilakukan.

Adapun beberapa permasalahan yang sedang dihadapi oleh SD Muhammadiyah 4 Kota Batu adalah sebagai berikut:

1. Masih banyak terdapat nama AUM yang terdaftar sebagai yayasan bukan persyarikatan

2. Terdapat perbedaan antara NPWP AUM dengan NPWP Pusat

3. Saat ini NPWP cabang dan pusat tidak melaporkan perpajakannya

4. Database belum tersetruktur

5. Penyajian laporan keuangan dan perpajakan belum memadai

Berdasarkan permasalahan tersebut, maka program pengabdian kepada masyarakat ini akan dilakukan secara berkelanjutan dan dibagi menjadi tiga tahap yaitu tahap pengurusan NIB, tahap Pelaporan keuangan dan perpajakan dan tahap tata kelola AUM. Adapun fokus permasalah yang akan diselesaikan pada tahapan ini adalah pengurusan NIB SD Muhammadiyah 4 Kota Batu.

Tim pengusul pada Pengabdian Masyarakat ini merupakan akademisi yang memiliki kompetensi sesuai dengan bidangnya yaitu kompetensi bidang akuntansi sektor publik, perpajakan dan keuangan. Kompetensi tersebut akan sangat mendukung dalam melakukan proses evaluasi, analisis dan penyelesaian permasalahan yang ada pada SD Miuhammadiyah 4 Kota Batu.

Kegiatan pengabdian kepada masyarakat ini memiliki luaran dan target kegiatan. Target yang ingin dicapai diantaranya adalah terciptanya ketertiban dan kelengkapan dalam administrasi pada SD Muhammadiyah 4 Kota Batu. Dengan lengkapnya dokumen yang dimiliki maka akan memberikan kemudahahan dalam kegiatan pelaporan baik keuangan maupun perpajakan. Selain itu, target kedua yang diharapkan dalam kegiatan ini adalah SD Muhammadiyah 4 Kota Batu memiliki Nomor Ijin Berusaha (NIB) dan juga terjadinya keseragaman NPWP yang bertujuan untuk menunjang aktvitas operasonal AUM. Adapun luaran yang diharapkan dari kegiatan ini, pertama yaitu SD Muhammadiyah Kota Batu memiliki NIB sehingga dapat mendaftarkan atau membenahi pembuatan NPWP. Luaran kedua yaitu adanya publikasi dalam jurnal nasional terakreditasi. 


\section{METODE}

Berdasarkan hasil identifikasi permasalahan yang ada pada SD Muhammadiyah 4 Kota Batu, kegiatan pengabdian ini akan dilakukan secara berkelanjutan. Namun, kegiatan pada tahun ini akan fokus pada penyelesaian permasalah AUM yaitu proses pengurusan administrasi NIB. Metode pendekatan yang akan ditawarkan adalah metode ceramah (presentasi), pelatihan, pendampingan dan dialog. Masing-masing metode akan digunakan untuk kegiatan berikut :

1. Metode Ceramah bertujuan untuk memberikan gambaran dan pemahan kepada masing-masing penanggungjawab dan pengelola AUM tentang pentingnya legalitas pendirian usaha melalui dengan menggunakan NIB

2. Metode Pelatihan dan Pendampingan bertjuan agar AUM dapat memahami dan menguasai prosedur perijinan, dan pengurusan NIB

3. Metode Dialog bertujuan untuk pemahaman lebih terkait permasalahanpermasalahan dari masing-masing AUM.

Kerangka pemecahan masalah yang dirancang untuk menunjang pencapaian tujuan dari kegiatan pengabdian kepada masyarakat dirumuskan sebagai berikut:

\begin{tabular}{|c|c|c|c|}
\hline Jenis Kegiatan & $\begin{array}{l}\text { Partisipasi } \\
\quad \text { Mitra }\end{array}$ & $\begin{array}{l}\text { Luaran } \\
\text { Kegiatan }\end{array}$ & $\begin{array}{c}\text { Solusi } \\
\text { Masalah }\end{array}$ \\
\hline 1. Sosialisasi NIB & $\begin{array}{l}\text { Mitra } \\
\text { menyiapkan } \\
\text { tempat } \\
\text { pertemuan dan } \\
\text { pelatihan }\end{array}$ & $\begin{array}{l}\text { Peserta } \\
\text { memahami } \\
\text { tujuan NIB dan } \\
\text { meningkatkan } \\
\text { motivasi dalam } \\
\text { mengikuti } \\
\text { agenda } \\
\text { selanjutnya }\end{array}$ & $\begin{array}{l}\text { Melibatkan } \\
\text { mitra dan } \\
\text { pemberian } \\
\text { motivasi untuk } \\
\text { meningkatkan } \\
\text { penertiban } \\
\text { administrasi }\end{array}$ \\
\hline $\begin{array}{l}\text { 2. Pelatihan dan demo } \\
\text { pembuatan legalitas }\end{array}$ & $\begin{array}{l}\text { Mitra sebagai } \\
\text { peserta, perlu } \\
\text { mempersiapkan } \\
\text { a. tempat } \\
\text { pelatihan dan } \\
\text { demo } \\
\text { b. Syarat-syarat } \\
\text { pembuatan NIB } \\
\text { (akte pendirian, } \\
\text { NPWP, sertifkat } \\
\text { tanah, foto } \\
\text { bangunan) }\end{array}$ & $\begin{array}{l}\text { Peserta mampu } \\
\text { membuat } \\
\text { perizinan dan } \\
\text { legalitas (NIB) }\end{array}$ & $\begin{array}{l}\text { Pembinaan dan } \\
\text { demontrasi } \\
\text { pembuatan } \\
\text { perizinan dan } \\
\text { legalitas (NIB) }\end{array}$ \\
\hline 3. Evaluasi dan monitoring & $\begin{array}{l}\text { Mitra sebagai } \\
\text { peserta }\end{array}$ & $\begin{array}{l}\text { Melakukan } \\
\text { monev. }\end{array}$ & Pendampingan \\
\hline
\end{tabular}

Tabel 1.

Metode

Pelaksanaan

Kegiatan

Keberhasilan dalam pencapaian tujuan kegiatan pengabdian kepada masyarakat ini perlu dukungan, partisipasi dan kerjasama dengan penanggungjawab dan pengola SD Muhammadiyah Kota Batu. Adapun bentuk dukungan, partsipasi dan kerjasama yang dilakukan dapat berupa perijinan dan penyediaan atas data/informasi yang dibutuhkan, kesediaan untuk mengikuti kegiatan pelatihan dan pendampingan, serta koordinasi atas kegiatan-kegiatan selama pelatihan dan pendampingan. 


\section{HASIL DAN PEMBAHASAN}

SD Muhammadiyah 4 Kota Batu merupakan salah satu Sekolah Dasar yang merupakan Amal Usaha Muhammadiyah (AUM). Sekolah ini berlokasi di Jalan Welirang, Kelurahan Sisir. Berdasarkan identifikasi masalah yang disampaikan sebelumnya, bahwa legalitas Sekolah masih mengalami kendala khususnya terkait dengan pembuatan Nomor Pokok Wajib Pajak (NPWP). NPWP sendiri merupakan bagian penting yang harus dimiliki oleh lembaga sekolah untuk melakukan kegiatan-kegiatan administratif seperti syarat untuk penerimaan dana bantuan operosional sekolah atau dana BOS. Sedangkan untuk mendaftarkan NPWP Sekolah terdapat beberapa syarat yang harus dipenuhi salah satunya adalah Nomor Induk Berusaha (NIB). Kurangnya pemahaman terkait pembuatan dan pengurusan NIB membuat pihak sekolah belum juga memiliki NIB maupun NPWP. Oleh karena itu, terkait dengan hal tersebut, tim pengabdian melakukan sosialisasi dan pendampingan pembuatan NIB dengan beberapa tahapan kegiatan, yaitu Sosialisasi NIB, Pelatihan dan Demo Pembuatan Perizinan dan Legalitas, dan Evaluasi dan Monitoring. Masing- masing kegiatan tersebut akan diuraikan berikut.

\section{Sosialisasi Nomor Induk Berusaha (NIB)}

Kegiatan sosialisasi Nomor Induk Berusaha (NIB) dilakukan dengan tujuan agar mitra dapat memahami tentang NIB dan juga pentingnya Institusi untuk memiliki NIB. Sebagaimana yang telah disampaikan pada Peraturan Pemerintah Nomor 24 Tahun 2018 tentang perizinan Berusaha Terintegrasi Secara Elektronik atau disebut Online Single Submission (OSS) sudah wajib dilaksanakan sejak bulan Juli 2018. NIB sendiri merupakan kebijakan baru dari pemerintah untuk memudahkan pengusaha dalam mengurus dan mendapatkan izin usaha. NIB juga merupakan identitas berusaha dan digunakan oleh pelaku usaha untuk mendapatkan izin usaha dan izin komersial atau operasional (https://voffice.co.id/jakarta-virtual-office/business-tips/apa-itu-nib-nomor-indukberusaha/)

Organisasi Muhammadiyah dalam hal ini memberikan fasilitasi kepada semua Amal Usaha Muhammadiyah (AUM) baik sektor kesehatan maupun Pendidikan seperti sekolah (SD Muhammadiyah 4 Kota Batu) melalui aplikasi secara online untuk pengurusan NIB. Aplikasi ini dibuat untuk dapat mempermudah pengurusan NIB tanpa harus datang ke Pimpinan Pusat Muhammadiyah untuk mendapatkan otorisasi secara langsung melainkan dapat dilakukan secara online. Aplikasi tersebut khusus diperuntukkan terkait pendaftaran Pengesahan Ijin Pendirian Amal Usaha Muhammadiyah dan juga pembuatan NIB. Pada aplikasi yang telah disediakan ini mitra harus melakukan dua tahapan untuk pengurusan NIB. Tahap pertama, mitra harus mengajukan dan membuat surat permohonan pengesahan AUM. Setelah surat permohonan dan pengesahan AUM diotorisasi oleh Pimpinan Pusat Muhammadiyah, maka dapat dilanjutkan pada tahap kedua yaitu pembuatan NIB.

Adapun yang disampaikan pada kegiatan sosialisasi tersebut terkait dengan persyaratanpersyaratan yang harus dilengkapi untuk mendaftarkan NIB mitra, diantaranya yaitu

1. Akte pendirian (IMB dan SHM)

2. Permohonan Izin operasional dari Dinas Pendidikan

3. Nomor Pokok Sekolah Nasional (NPSN)

4. Scan sertifkat tanah yang terdiri dari file sertifikat halaman identitas dan file sertifikat halaman ukur

Janayu 1.2 
5. Foto bangunan tampak depan dan belakang (ukuran maksimal $300 \mathrm{~kb}$ dalam format JPG/JPEG/PDF/PNG)

6. Stempel PDM

Tabel 2. Susunan Struktural SD Muhammadiyah 4 Kota Batu

\begin{tabular}{cll}
\hline No & \multicolumn{1}{c}{ Jabatan } & \multicolumn{1}{c}{ Nama } \\
\hline 1. & Kepala Sekolah & Mariani, S.Pd \\
\hline 2. & Waka Kurikulum & Anifah Noor Aida, S.Pd \\
\hline 3. & Waka Kesiswaan & Saiful Amin, S.Pd \\
\hline 4. & Waka Humas & Lilis Wahyuningrum, S.Pd \\
\hline 5. & Waka Sarpras & Nur Ita Rahmawati, SH \\
\hline 6. & Staf IT & Ferdi Nuriansyah \\
\hline
\end{tabular}

Tabel 2.

Susunan

Struktural SD

Muhammadiyah

4 Kota Batu

Pada kegiatan sosialisasi tersebut dihadiri oleh staf IT dan juga beberapa struktural yang ada di SD Muhammadiyah 4 untuk dapat diberikan pemahaman terkait NIB dan pentingnya NIB bagi Instansi mitra. Adapun struktural yang hadir dalam kegiatan tersebut dapat dilihat dalam Tabel 1.

\section{Pelatihan dan Demo Pelatihan Pembuatan Legalitas}

Pelatihan dan Demo pembuatan legalitas dilakukan di SD Muhammadiyah 4 Kota Batu yang terletak di Jl. Welirang No.17, Sisir, Kec. Batu, Kota Batu. Pelatihan dilakukan pada 5 Maret 2020 pukul 09.00-12.00 WIB yang diikuti oleh Kepala Sekolah, Wakil Kepala Sekolah, Bendahara dan Tim IT SD Muhammadiyah 4 Kota Batu. Demo pelatihan pembuatan legalitas meliputi Nomor Izin Berusaha (NIB) dan Nomor Pokok Wajib Pajak (NPWP), dimana peserta diajarkan demo pembuatan NIB secara online dan menyiapkan data yang dipenuhi untuk pembuatan NPWP. Pentingnya pelatihan legalitas karena untuk saat ini ada beberapa izin yang digantikan, Izin yang digantikan dengan NIB adalah TDP (Tanda Daftar Perusahaan), API (Angka Pengenal Impor), juga akses kepabeanan sebagai eksportir dan importir.

Selama pelatihan dan demo pembuatan legalitas mitra berperan aktif semua data yang dibutuhkan untuk pembuatan NIB diantaranya IMB, SHM, Permohonan Izin operasional dari Dinas Pendidikan, izin pendirian, nomor pokok sekolah nasional (NPSN), Foto Bangunan tampak depan dan dalam sudah tersedia semua sehingga pembuatan NIB secara online dapat berjalan dengan lancar. Selain pengisian data pengajuan NIB secara online, pendamping juga memberikan informasi mengenai prosedur pembuatan NPWP bahwasannya NPWP untuk amal usaha muhammadiyah harus berdiri sendiri tidak boleh menggunakan nama "yayasan" hal tersebut dimaksudkan untuk menghindari adanya dobel dalam pembayaran pajak.

Janayu 1.2

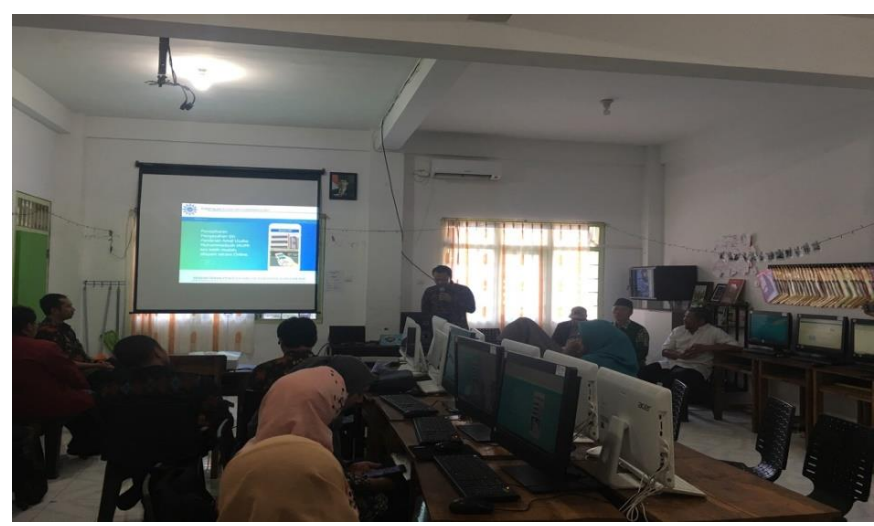

Gambar 2.

Proses

Pelatihan

Pembuatan

NIB 

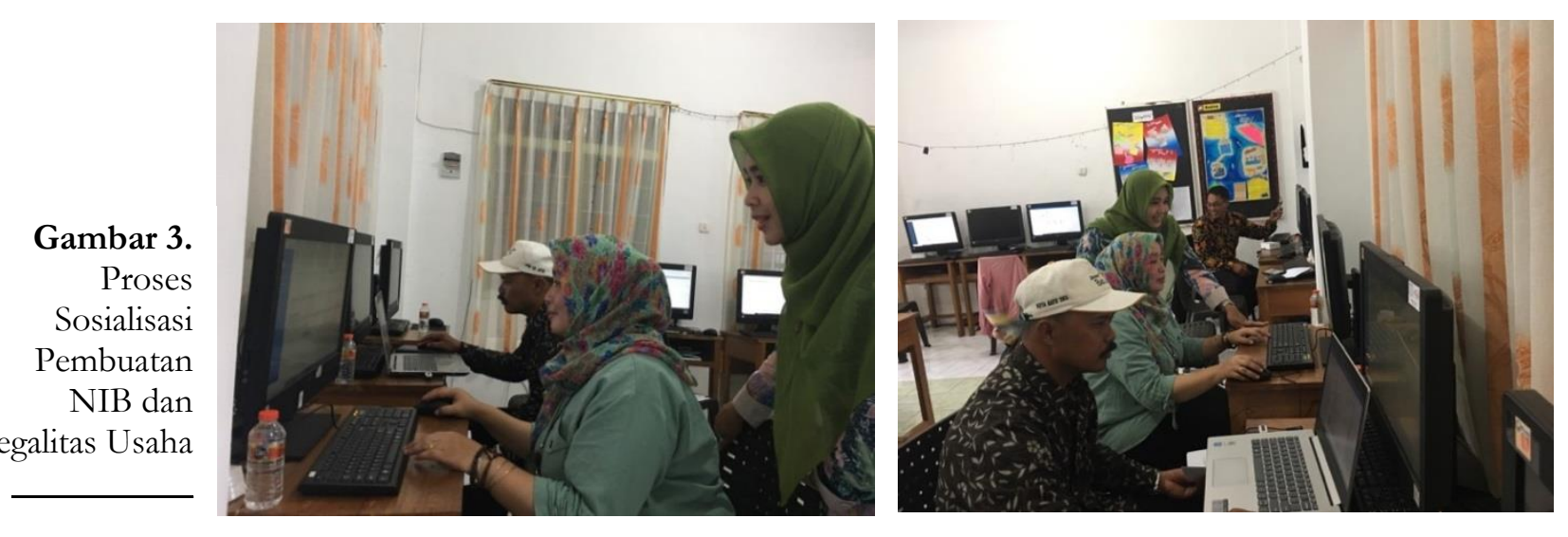

\section{Evaluasi dan Monitoring}

Kegiatan pendampingan yang telah dilakukan tentunya tidak terlepas dengan adanya evaluasi dan monitoring. Kegiatan ini ditujukan agar dapat melakukan monitoring dan evaluasi atas kegiatan pendampingan sehingga dapat menjawab pertanyaan apakah kegiatan pendampingan yang selama ini telah dilakukan berjalan lancar atau memiliki kendala yang berarti sehingga dapat segera dilakukan follow up lebih lanjut. Adapun kegiatan monitoring dan evaluasi dilakukan selama dua minggu setelah kegiatan pendampingan dilakukan yaitu 6-20 Maret 2020.

Proses monitoring yang dilakukan dengan mitra ini dilakukan secara online melalui komunikasi via telepon ataupun whatsapp. Dari hasil monitoring dan evaluasi dapat diketahui bahwa kendala yang masih berjalan saat ini adalah mitra masih harus menunggu Surat Keputusan (SK) pengesahan dari Pimpinan Pusat Muhammadiyah agar dapat dilanjutkan untuk mengajukan pembuatan NIB. Proses pengesahan dari Pimpinan Pusat Muhammadiyah dikarenakan antrian yang cukup Panjang, dari sekian AUM yang sedang mengajukan Surat Pengesahan dari seluruh AUM yang ada di Jawa Timur dan Jawa Barat.

\section{SIMPULAN}

Kegiatan pengabdian masyarakat pada SD Muhammadiyah 4 Kota Batu pada dasarnya mendapatkan respon yang positif sehingga kegiatan pendampingan pembuatan NIB pun berjalan lancar. Proses penerbitan NIB tinggal menunggu Surat Keputusan (SK) dari Pimpinan Pusat Muammahdiyah. Kegiatan pengabdian ini membutuhkan waktu relative Panjang terakit dengan waktu penerbitan Surat Keputusan dari Pimpinan Pusat Muhammadiyah.

\section{DAFTAR PUSTAKA}

Akbar, M. F., Suprapto, S. H., \& Mohi, W. K. (2018). Deskripsi Budaya Organisasi dalam Amal Usaha Muhammadiyah (Studi Kasus Universitas Muhammadiyah Gorontalo). ARISTO, 7(1), 34-45.

Arif Rohman \& Teguh Wiyono. (2010). Education policy in decentralization era. Yogyakarta: Pusataka Pelajar.

Gusfira Nofil . (2017). Strategi Dan Dinamika Muhammadiyah Di Takengeon. Jurnal AsSalam STAI Darussalam Lampung,Vol.1(3), 16-29. 
Khozin. 2005. Menggugat Pendidikan Muhammadiyah. Malang: Universitas Muhammadiyah Malang (UMM) Press.

Purba, I. A., \& Ponirin, P. (2017). Perkembangan Amal Usaha Organisasi Muhammadiyah di Bidang Pendidikan dan Kesehatan. JPPUMA Jurnal Ilmu Pemerintahan dan Sosial Politik Universitas Medan Area, 1(2), 101-111.

Subarkah, Abdillah.M. (2017. Muhammadiyah Dan Amal Usaha Di Bidang Pendidikan. Jurnal Rausyan Fikr IAIN Pali, 13 (2).

Susilo, M. J. (2016). Kajian kemandirian sekolah di amal usaha mubammadiyah. Pubikasi Ilmiah Universita Muhammaiyah Solo.

Peraturan Pemerintah Nomor 24 Tahun 2018 tentang perizinan Berusaha Terintegrasi Secara Elektronik atau disebut Online Single Submission (OSS)

Zamroni. (2007). Meningkatkan mutu sekolah: Teori, strategi, dan prosedur. Jakarta: PSAP Muhammadiyah. 